\title{
As Perspectivas de Avaliar o Estudante no Ensino Híbrido
}

\author{
Edson Pedro Schiehl ${ }^{1}$, Avanilde Kemczinski ${ }^{1,2}$, Isabela Gasparini ${ }^{1,2}$ \\ Departamento de Ciência da Computação - PPGECMT ${ }^{1}$ e PPGCA ${ }^{2}$ \\ Universidade do Estado de Santa Catarina (UDESC) - Joinville, SC - Brasil \\ edschiehl@gmail.com, avanilde.kemczinski@udesc.br, isabela.gasparini@udesc.br
}

Resumo. Este trabalho foi construído com base no estado da arte, com foco nas formas de avaliar o estudante em ambientes de ensino híbrido. Traz um retrato de como as avaliações são pensadas no meio educacional e como são desenvolvidas. Nos trabalhos relacionados pode ser verificado que entre as formas de avaliar, a formativa é a estratégia para promover melhor desempenho no processo de ensino-aprendizagem. No entanto, requer condições tecnológicas que auxiliem nas etapas e aplicações das avaliações possibilitando diagnosticar dificuldades $e$ implementar melhorias na avaliação do estudante no ensino híbrido.

Palavras-chave: Ensino Híbrido, Avaliação Formativa, Ensino e Aprendizagem.

\section{The Perspectives of Evaluating the Student in Blended Learning}

\begin{abstract}
This work was built by the state of the art in the ways of assessing the student in hybrid teaching environments. It gives a picture of how assessments are thought in the educational environment and how they are developed. In the related works it can be verified that among the ways to evaluate, formative is the strategy to promote better performance in teaching and learning. However, it requires technological conditions that help in the stages and applications of the evaluations, making it possible to diagnose difficulties and implement improvements in this complex process that evaluate the student.
\end{abstract}

Keywords: Blended Learning, Formative Evaluation, Teaching and Learning.

\section{INTRODUÇÃO}

Os processos de ensino e aprendizagem tradicionais não atendem mais o estudante do século XXI, muito menos as demandas desse mundo contemporâneo (ANDRADE e DE SOUZA, 2016). Uma realidade que requer inovações urgentes, mas que não rompa agressivamente com o modelo que se disseminou em nós e em nossos estudantes. Pois, à coerência em pensar nas mudanças tecnológicas para dinamizar o aprendizado com o fato de que precisa ser conduzida com planejamento e aplicações controladas. O objetivo é evoluir, sem criar uma ação momentânea e retornar ao mesmo cenário tradicional pelo simples descuido pedagógico.

A inserção da tecnologia nas práticas pedagógicas foi conquistando espaço pelas demonstrações e benefícios nesse meio. Aos poucos a mistura de aulas face a face com o uso de tecnologias se torna algo que desenvolve a educação em qualquer lugar e a qualquer tempo (ZANOTTO et al, 2014). Surge então o ensino híbrido, do inglês blended learning, que combina o currículo a ser desenvolvido pelas instituições por meio dos professores usando as mais diversas tecnologias on-line (CHRISTENSEN, HORN e STAKER, 2013). Uma relação que segundo Moran (2015) efetiva-se com o conjunto de ambientes físicos aos 
elementos tecnológicos, o que possibilita ampliar o conhecimento no mundo virtual. Para isso, cada instituição precisa analisar como pode organizar e implantar um ou mais modelos de ensino híbrido existentes (BACICH, TANZI NETO e TREVISANI, 2015).

O processo de implementar um ou outro modelo de ensino híbrido demanda de planejamento para uma boa execução. Com tudo a avaliação e as métricas aplicadas demonstram o quanto esse modo de ensino pode ser eficiente e/ou eficaz para o que se pretende. Porém, como é possível determinar qual é a melhor métrica e quais parâmetros devem ser avaliados para definir se o modelo de ensino híbrido atende o que foi planejado e se surtiu efeitos positivos ou negativos nessa implementação?

Assim, esse artigo busca no estado da arte encontrar: o que se pensa e o que se utiliza como forma de avaliar o estudante no ensino híbrido. Outro objetivo é descrever as métricas que foram utilizadas em cada trabalho. Com essa intenção as seções do artigo estão descritas em: Fundamentação teórica, que abordam o ensino híbrido e avaliação na seção 2; Trabalhos relacionados que retratam os artigos sobre o assunto em questão na seção 3; Discussão, no qual o artigo pauta as argumentações dos resultados encontrados na seção 4; Na seção 5 as considerações finais e por fim as referências.

\section{FUNDAMENTAÇÃO TEÓRICA}

O movimento de combinar elementos tecnológicos no ensino e aprendizagem é relatado nos estudos de Güser e Caner (2013), que observaram em trabalhos conduzidos no início do século XXI, abordavam uma mistura de atividades escritas com jogos, no ensino da pré-escola. Em outros experimentos observaram como programas de treinamento em liderança envolviam as instruções dos professores e o uso de e-learning (GÜSER e CANER, 2013). Também destacam na abordagem do uso de aprendizagem assíncrona e os estudos desenvolvidos face a face com o instrutor. Assim, Güser e Carner (2013) definem como um período inicial do ensino híbrido que tinha como principal objetivo apoiar o aprendizado on-line com a aprendizagem face a face. A partir de então, vários estudos puderam organizar os aspectos positivos e discutir fatores negativos ao se trabalhar com as misturas de ensino e de aprendizagem.

O ensino híbrido não tem uma definição determinada. Ele é como o próprio nome retrata, uma mescla, combinação, mistura de inúmeros métodos, formas, jeitos e técnicas que podem conduzir ao ensino de um certo conteúdo. Pode se dizer que é um contexto macro que envolve, desde atitudes simples as mais complexas na intenção de se fazer educação (MORAN, 2015). Por isso é que somos, ao mesmo tempo, aprendizes e mestres interagindo em uma esfera que proporciona grandes desafios e inovações, estabelecendo a abrangência indubitável do que é o termo híbrido na educação.

Com a modernidade das empresas, as universidades puderam apoiar seus estudos nessa abordagem e utilizar conceitos que promoveram inovações no mercado para adaptar em ações que pudesse mudar a forma de se fazer educação (CHRISTENSEN, HORN e STAKER, 2013). No mapeamento sistemático da literatura de Goudouris e Struchiner (2015), o uso do ensino híbrido em medicina, constatou que após os anos de 2010 houve um grande volume de trabalhos envolvendo a forma híbrida de trabalhar conteúdos para o aprendizado do estudante. Em outro trabalho recente, Bacich, Tanzi Neto e Trevisani (2015) organizam um trabalho com vários experimentos no uso do ensino híbrido em sala de aula e descreveram como os modelos foram aplicados e quais foram as melhorias obtidas na forma de ensinar e aprender. 
Para Horn e Staker (2015), o ensino híbrido que objetiva reunir os métodos tradicionais com ambientes virtuais para o ensino e aprendizagem está dividido em duas linhas de aplicação: a forma sustentada e a disruptiva. Nas instituições que desenvolvem o processo de ensino e aprendizagem sustentado, muitos aspectos do modelo tradicional são mantidos. O formato da sala de aula, o currículo e os profissionais adaptam as situações para o melhor envolvimento e desenvolvimento do estudante, agregando atividades diversificadas, tecnologias e modelos mais flexíveis com a estrutura e as condições da instituição. (MORAN, 2015b). Para as instituições inovadoras com características mais disruptivas ao tradicional, Moran (2015b) destaca que essas determinam mudanças significativas, tanto na estrutura física quanto na pedagógica. Cabe ressaltar que os entusiastas dos modelos sustentados ou disruptivos definem que cada instituição personalizam um modelo as suas práticas educacionais, usando as inovações como apoio ao processo de ensino e aprendizagem para a geração de nativos digitais.

Cabe ainda pensar como a avaliação é pensada nesse método de ensino e a aprendizagem, pois a mistura de elementos tecnológicos com o tradicional desponta novas formas de avaliar, será?

Assis (1997) descreve o uso da avaliação escola brasileira do século XIX, como a forma de decidir se o estudante avança ou não em seu nível de escolarização. Esse processo avaliativo foi muito utilizado como forma de forçar a memorização e até para amedrontar ou punir o estudante (LUCKESI, 2002). No entanto, muitos se perguntam, dois séculos atrás? Mas parece que esse formato ainda é utilizado por muitas instituições nesse século. Herdada de um momento histórico, que cumpria seu papel naquela época desafia muitos contemporâneos a quebrar esse paradigma. Além disso, a reflexão sobre a avaliação precisa ir além de sua readequação de uso e sentido (RODRIGUES, 2015, p.124). O movimento tecnológico, métodos e modelos educacionais inovadores e estudantes nativos digitais combinam possibilidade para mudanças imediatas.

Alguns autores definem que a avaliação é uma ação necessária para medir (dar valor) o ensino-aprendizagem e normalmente, relacionam três funções nesse processo, que são: diagnóstica, formativa e somática (SILVA, DEUSA e MARQUES, 2016). Na função diagnóstica procura constatar se o estudante possui os conhecimentos e habilidades necessários para ancorar novos conhecimentos. Pela função formativa o docente tem uma visão do desenvolvimento das atividades, como uma forma de controle do rendimento de cada estudante, bem como melhorar as deficiências na condução do ensino e da aprendizagem. Já a função somática tem o objetivo de classificar e pressupõem quem possa ou não avançar a outro nível (SILVA, DEUSA e MARQUES, 2016).

Assim, uma produção com o estado da arte sobre a avaliação no ensino: híbrido, combinado ou misturados foi construído para entender e discutir o assunto. Na próxima sessão os trabalhos relacionados descrevem artigos que trazem essa abordagem.

\section{TRABALHOS RELACIONADOS}

A pesquisa focou em encontrar artigos que abordassem o uso do ensino híbrido e seus similares (combinado ou misturado) e apresentassem elementos caracterizando a avaliação utilizada nesse modelo. Estabelecendo o critério que envolvesse o "Ensino Híbrido” mais “Avaliação”, a pesquisa foi efetuada no repositório do Google Acadêmico, por estar entre os melhores mecanismos de busca, segundo o trabalho de Buchinger, Cavalcanti e Hounsell (2012). 
Entre os resultados obtidos nessa pesquisa, o trabalho de Da Silva (2016), explora a avaliação em teia ${ }^{1}$ na disciplina de matemática. Esse experimento foi conduzido em escola pública de Maceió, Alagoas, aplicado a quarenta e seis estudantes do ensino básico. $\mathrm{O}$ autor descreve que essa forma de avaliação é contínua da aprendizagem e mediada pela tecnologia. Com o uso do Google Formulários o professor constrói diversos problemas e trajetórias em que o estudante pode ou precisa percorre. A proposta utiliza questões que abordam elevação nos níveis de conceituação e complexidade a cada resposta certa que pode ser escolhida pelo estudante que opta pelo nível básico ou mais conceitual. Já nas questões em que o estudante erra, automaticamente é conduzido para uma questão mais simples (DA SILVA, 2016).

Com base na Teoria de Resposta ao Item² ${ }^{2}$ Da Silva (2016), a teia é modelada com diversos problemas e com níveis diferentes de complexidades. Além disso captura traços ou características dos respondentes determinando se ele possui domínio no conteúdo que lhe é proposto. A questão é pontuada de acordo com as habilidades de: discriminação, dificuldade e adivinhação, sendo o mesmo requisito utilizado nas provas do ENEM. Assim, o estudante que errar tudo não tem zero e nem se acertar tudo dez como nota pelo critério de que ninguém não sabe nada e nem é detentor do conhecimento pleno (DA SILVA, 2016).

Ao aplicar o experimento o Da Silva (2016) diz que esse estilo de avaliação em teia “é prospectivo e evidencia os dados qualitativos; seu escopo é compreender a relação entre o aprendizado e o desenvolvimento das funções psicológicas superiores”. Nas colocações dos resultados das interações que os estudantes tiveram ao responder o questionário relatou que vários estudantes utilizaram da opção ajuda para evoluir no questionário e que a maioria acertava logo depois. Contudo, a eficiência e eficácia desse estudo não ficou comprovada com métricas estatísticas que comparassem a evolução dos estudantes, mas comprometeu-se em continuar a pesquisa e disponibilizar futuramente melhores resultados.

Na pesquisa de Silva, Deusa e Marques (2016), defendem o uso de uma avaliação formativa e midiática, pois torna a escola mais completa e propicia a construção da educação nos modelos híbridos. Nessa perspectiva o estudo foi aprofundado no experimento de utilizar o MOODLE como ambiente virtual de aprendizagem (AVA), no qual os estudantes interagiam. As atividades desenvolvidas em sala deveriam ser registradas no AVA, como um diário de bordo. O diário deveria ser escrito em primeira pessoa, usando a coerência na linguagem primar pela forma culta do português, também observariam o volume dos trabalhos, cuidados com os conceitos e pontualidade (Silva, Deusa e Marques, 2016).

Assim, Silva, Deusa e Marques (2016) observaram que a avaliação da produção dos diários de bordo pelos estudantes envolvendo as características citadas no parágrafo anterior prospectam um envolvimento e entendimento da sala de aula pelo professor. Com esse modelo de avaliação formativa, subsidiou ações mais assertivas ao professor em promover um melhor ensino e aprendizagem. No entanto, também não mensurou dados com métricas estatísticas que comprovassem a eficiência ou eficácia do método.

\footnotetext{
${ }^{1}$ A avaliação em teia integra-se como ramificações de atividades mais simples a elevação de níveis de complexidade para resolução (DA SILVA, 2016).

${ }^{2}$ Teoria de Resposta ao Item - TRI - é um direcionamento ao estudo de questionários ou lista de itens. Analisa as assertivas em relação ao chute ou acerto por conhecimento (DA SILVA, 2016).
} 
Tanzi Neto, Schneider e Bacich (2016) relatam um experimento do modelo do ensino híbrido - laboratório rotacional. Ele foi aplicado na disciplina de língua inglesa ao terceiro ano do ensino técnico integrado em um Instituto Federal de Educação, Ciências e Tecnologia. O trabalho traz um retrato geral de como a tecnologia já é realidade em qualquer que seja o lugar e que mesmo que a escola não possua muitos recursos, ainda sim as combinações de ensino podem ocorrer. No experimento utilizaram na execução das atividades o livro didático e a construção de mapas conceituais no laboratório de informática. Os resultados ficaram na maior parte destinados a mostrar que o modelo requer planejamento e envolvimento do professor, estudante e gestão, para que se tenha melhores resultados. No entanto, o quesito avaliação ficou somente especificada que iria ser observado a elaboração dos mapas conceituais e não demostrou nenhuma métrica para analisar possíveis evoluções no desempenho ou aprendizagem dos estudantes.

Andrade e De Souza (2016) relataram brevemente algumas atividades utilizando o modelo de rotação por estações e a sala de aula invertida. Nas experiências do modelo de rotação por estações, destacaram diversos benefícios, como: a oportunidade do professor trabalhar em grupos menores e fornecer feedbacks em tempo útil, oportunizando o aprendizado individual e colaborativo, além dos acessos tecnológicos que permitiram novas formas de ensinar e aprender (Andrade e De Souza, 2016). Com o modelo de sala de aula invertida destacam que o compromisso e a responsabilidade é, tanto do professor quanto do estudante, porém, a metodologia auxilia no desenvolvimento da autonomia do estudante (Andrade e De Souza, 2016).

As análises de Andrade e De Souza (2016) destacaram os aspectos qualitativos do uso de modelos híbridos e não os quantitativos. Sutilmente relatam em um dos experimentos que as interações nas atividades on-line pontuavam os estudantes para classificar o seu esforço e participação. Essa prática de indicar um valor numérico as atividades de participação dos estudantes em atividades como o de participação, esforço ou interação, Costa et al (2012) explica que é uma prática comum nas instituições de ensino, pelo fato de ter que relacionar o que o estudante desenvolveu ou aprendeu com uma nota.

Valente (2014), também faz um parecer de como a sala invertida é utilizada nos modelos semipresenciais e ensino à distância (EAD). Porém, aborda um pouco mais sobre as práticas de avaliação aplicadas nesse tipo de curso. Inicialmente o estudante deve estudar seu material em casa, ou em qualquer outro ambiente e depois realizar algumas atividades on-line para verificar se o assunto foi assimilado. Nos momentos de encontros presenciais (modelo semipresencial) as avaliações do que foi estudado em web aulas e nos impressos são aplicadas avaliações formais para atribuição de nota ou conceito e somada as outras atividades determina se o estudante avança de nível ou deverá repetir esse módulo (conteúdo). Para as instituições mais críticas em relação ao ensino e aprendizagem, utilizam os parâmetros das avaliações para analisar e discutir e aplicar melhorias em momentos oportunos. Por fim, descreve que a autoavaliação é um outro método que permite diagnosticar eventuais falhas no processo de aprendizagem do estudante e estas podem ser modificadas imediatamente ou futuramente conforme a análise do professor e instituição (Valente, 2014).

Alguns cenários de ensino podem adotar uma postura mais virtual no tratamento avaliativo, como é o caso aplicado em algumas instituições de ensino superior que utilizam o modelo híbrido de sala de aula invertida (PIVA JR. et al, 2016). Ainda destacam a utilização de um sistema adaptado ao gerenciamento do processo formativo do estudante, pois ao utilizar o sistema de avaliação da aprendizagem no ensino superior, pode ser a 
diferença em diagnosticar e adaptar estratégias ao ensino e o aprendizagem. Entende-se que a complexidade em dimensionar uma avaliação formativa e que disponibilize ao professor informações em tempo real só é possível com um sistema de avaliação (PIVA JR. et al, 2016).

Assim, as contribuições dos artigos supracitados nessa seção vêm contribuir para uma análise dos caminhos que podem ser sugeridos e adaptados nos mais diversos níveis e contextos da educação que utilizam ou utilizaram os modelos de ensino híbrido.

\section{DISCUSSÕES}

O cenário educacional que se mostra na atualidade é de dualidade. De um lado, a desacreditada escola tradicional e seus métodos de ensino e de avaliação dos séculos passados, os quais não mais atendem ao estudante e a sua comunidade. No outro lado, os modelos virtuais de ensino que ainda não se consolidaram no meio educacional pelas diversas alternativas e por desconfianças (RODRIGUES, 2015).

Como o ensino híbrido possui a pretensão de unir as duas pontas, tradicional e tecnológico, pode-se até pensar que o problema ficará maior com a dualidade citada no parágrafo anterior. Para que isso não aconteça é preciso primeiro pensar que escola é uma comunidade e muitas coisas precisam ser observadas e discutidas ao aplicar mudanças. Outro ponto a se cuidar, nesse movimento tecnológico, é para não se torne uma tecnofilia e muito menos uma tecnofobia (RODRIGUES, 2015). Por fim, necessita alinhar o que se tem de melhor em cada um dos meios: tradicional e tecnológico, transformando-os em um sistema adequado a comunidade escolar.

Para conhecer os modelos de ensino híbridos, suas características e aplicabilidade, pode acessar o link https://goo.gl/H3LFyu (SCHIEHL e GASPARINI, 2016). Andrade e De Souza (2016) também abordam um dos modelos híbridos, nos trabalhos relacionados, rotação por estações. Esse modelo possibilita dividir a sala em diversos grupos e assim atendendo em tempo útil os estudantes que trabalham momentos de forma individual e outros coletivamente. O contato direto com estudante no que surge as dúvidas gera uma segurança e permite a continuidade dos trabalhos, progredindo em seus estudos.

Nessa perspectiva a avaliação precisa ser muito bem estruturada para alertar momentos que se postulem como frágeis, mas também, reconheça ações que possibilitem bons resultados no ensino e na aprendizagem.

Com as contribuições dos trabalhos relacionados, encontrou-se alguns caminhos que estão sendo estudados, trilhados e que alinham formas de se desenvolver a avaliação no ensino híbrido. No Quadro 1 destaca os principais elementos identificados nos artigos relacionados.

\begin{tabular}{|l|l|l|l|l|l|l|}
\hline Autores & $\begin{array}{l}\text { Modelo } \\
\text { Ensino } \\
\text { Híbrido }\end{array}$ & $\begin{array}{l}\text { Tipo de } \\
\text { avaliação }\end{array}$ & Métricas & Ferramentas & Público & Resultados \\
\hline
\end{tabular}




\begin{tabular}{|c|c|c|c|c|c|c|}
\hline 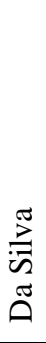 & 売 & 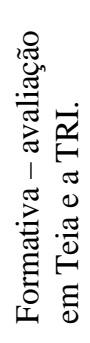 & $\begin{array}{l}\text { Tabela } \\
\text { descritiva dos } \\
\text { auxílios ao } \\
\text { estudante }\end{array}$ & $\begin{array}{l}\text { WIMS - } \\
\text { WWW } \\
\text { Interactive } \\
\text { Multipurpose } \\
\text { Server }\end{array}$ & $\begin{array}{l}\text { Primeiro } \\
\text { Semestre } \\
\text { da } \\
\text { Graduação } \\
\text { em } \\
\text { Matemática }\end{array}$ & $\begin{array}{l}\text { Com o uso do WIMS aplicando } \\
\text { avaliação em teia o professor } \\
\text { conseguiu acompanhar cada } \\
\text { estudante em seu } \\
\text { desenvolvimento. Desde os que } \\
\text { necessitaram de auxílios extra } \\
\text { para resolver suas atividades } \\
\text { aos que conseguiram evoluir } \\
\text { dinamicamente. }\end{array}$ \\
\hline 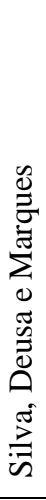 & 营 & 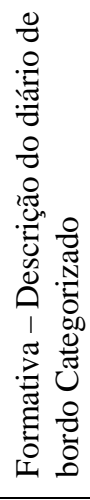 & $\begin{array}{l}\text { Relato geral } \\
\text { das interações } \\
\text { avaliando as } \\
\text { cinco } \\
\text { categorias na } \\
\text { produção do } \\
\text { diário. }\end{array}$ & Moodle & $\begin{array}{l}\text { Graduação } \\
\text { em } \\
\text { Matemática }\end{array}$ & $\begin{array}{l}\text { O uso do Moodle auxiliou nas } \\
\text { interações com os estudantes e } \\
\text { de acompanhamento constante. } \\
\text { A definição de avaliar em cinco } \\
\text { categorias possibilitou } \\
\text { identificar e orientar de forma } \\
\text { direta as dificuldades de cada } \\
\text { estudante. No entanto percebe- } \\
\text { se que o professor precisa estar } \\
\text { logado muito tempo para que os } \\
\text { feedbacks atenda às } \\
\text { necessidades dos estudantes } \\
\text { naquele momento. }\end{array}$ \\
\hline 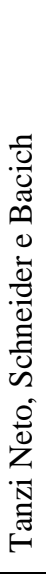 & 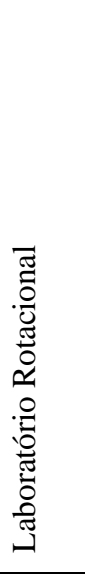 & 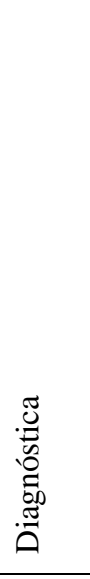 & $\begin{array}{l}\text { Construção } \\
\text { dos mapas } \\
\text { conceituais } \\
\text { com } \\
\text { verificação } \\
\text { das relações } \\
\text { desenvolvidas } \\
\text { pelos } \\
\text { estudantes. }\end{array}$ & Cmaps Tools & $\begin{array}{l}\text { Terceiro } \\
\text { ano do } \\
\text { Ensino } \\
\text { Técnico } \\
\text { Integrado } \\
\text { (Médio) }\end{array}$ & $\begin{array}{l}\text { Foi relatado no artigo que } \\
\text { envolver o estudante em } \\
\text { diversos ambientes da escola } \\
\text { onde ele é protagonista do seu } \\
\text { desenvolvimento e na sua } \\
\text { autonomia. O professor } \\
\text { permaneceu em sala de aula, } \\
\text { onde auxiliou nas dúvidas dos } \\
\text { estudantes. Na sala } \\
\text { informatizada os estudantes } \\
\text { trabalharam de forma } \\
\text { colaborativa e autônoma. } \\
\text { Assim, essa forma de trabalho } \\
\text { colaborou com a melhora do } \\
\text { desempenho dos estudantes. }\end{array}$ \\
\hline 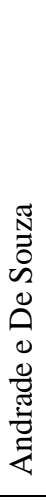 & 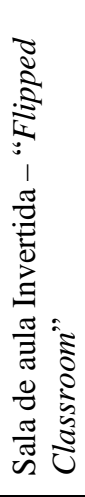 & 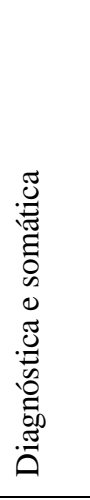 & $\begin{array}{l}\text { Utilização de } \\
\text { Rubricas }\end{array}$ & Edmodo & $\begin{array}{l}\text { Ensino } \\
\text { Médio }\end{array}$ & $\begin{array}{l}\text { Os estudantes assistiam os } \\
\text { vídeos em momentos anteriores } \\
\text { a aula e posteriormente } \\
\text { desenvolviam atividades em } \\
\text { sala com auxílio de quizzes on- } \\
\text { line. Os estudantes foram } \\
\text { avaliados pelas interações para } \\
\text { ser atribuído uma nota } \\
\text { classificatória nos fóruns. } \\
\text { Porém recebiam constantes } \\
\text { feedback nessas interações o } \\
\text { que auxiliava nas evoluções das } \\
\text { atividades. }\end{array}$ \\
\hline
\end{tabular}




\begin{tabular}{|c|c|c|c|c|c|c|}
\hline$\frac{\stackrel{0}{0}}{\frac{0}{0}}$ & 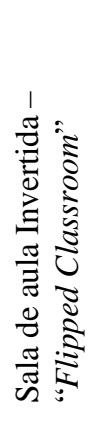 & 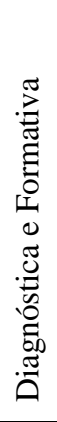 & $\begin{array}{l}\text { Análise por } \\
\text { participação e } \\
\text { assertividades } \\
\text { nas atividades } \\
\text { avaliativas } \\
\text { computadas } \\
\text { na } \\
\text { plataforma. }\end{array}$ & $\begin{array}{l}\text { Plataforma } \\
\text { própria e não } \\
\text { identificada }\end{array}$ & Graduação & $\begin{array}{l}\text { O processo avaliativo acontece } \\
\text { em diversas atividades on-line e } \\
\text { presenciais. As quais contribui } \\
\text { com a análise e atuação do } \\
\text { professor em melhorias } \\
\text { constantes no material e } \\
\text { abordagem do ensino. O } \\
\text { acompanhamento reflete em } \\
\text { estudantes mais preparados e } \\
\text { atuantes no seu aprendizado, } \\
\text { segundo autor. }\end{array}$ \\
\hline 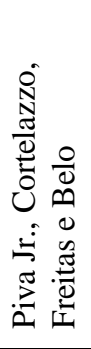 & 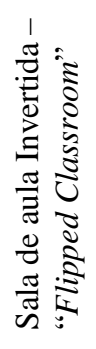 & 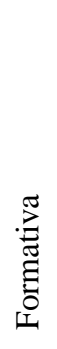 & $\begin{array}{l}\text { Estatísticas } \\
\text { de: evolução, } \\
\text { desempenho e } \\
\text { interatividade. }\end{array}$ & $\begin{array}{l}\text { Plataforma } \\
\text { SAA }\end{array}$ & Graduação & $\begin{array}{l}\text { Com a ferramenta SAA o } \\
\text { professor acompanha a } \\
\text { evolução, o desempenho e suas } \\
\text { interações no sistema. } \\
\text { Avaliando a necessidade de } \\
\text { retomada ou reforço em } \\
\text { conteúdo específico, no qual o } \\
\text { estudante demonstra } \\
\text { dificuldade. }\end{array}$ \\
\hline
\end{tabular}

Quadro 1 - Demonstrativo de escolha das turmas para aplicação do modelo de rotação Fonte: produção do próprio autor, 2017, baseada na ABNT/NBR 14724

As abordagens mais incisivas sobre o contexto é que uma avaliação não pode mais ser classificatória, onde o sujeito é simplesmente escolhido para passar ou permanecer em um nível. Os aspectos que envolve toda a construção do conhecimento deve ser levando em conta e nunca a uma única prova que define se é ou não detentor de certo assunto. Portanto, as avaliações de função somática que tem esse papel de classificar sugerem-se adaptar outros métodos avaliativos mais completos, como os de função diagnóstica e principalmente os de função formativa.

$\mathrm{Na}$ avaliação de função diagnóstica, os trabalhos relacionados citados, direcionam ao reconhecimento do que o estudante já sabe sobre determinado assunto. A partir deste diagnóstico planeja-se os caminhos que serão percorridos no processo de ensino e de aprendizagem. Contudo, o professor deve ter ciência de que ao usar essa forma de avaliação como parâmetro para nota, tende a ser mais um formato classificatório do que estratégico.

Já na avaliação de função formativa é notoriamente citada nos artigos, pois os autores percebem que avaliar o aprendizado somente no fim do curso, é falho. A aprendizagem é um processo continuo e que precisa usar meios que possibilite o professor a aplicar ações que corrijam o curso ensino e ao estudante entender suas dificuldades para viabilizar sua aprendizagem (PERRENOUD, 1999). Perrenoud (1999) ainda corrobora em seus estudos que a função formativa consiste em ajustar de modo mais organizado e pontual as atividades que auxiliam o estudante a obter melhores resultados.

Portanto, para ajudar a alcançar esse propósito, as metodologias de ensino híbrido propõem que o ensino-aprendizagem seja em parte por meio de os ambientes virtuais, tais como: plataformas, sistemas e aplicativos, que auxiliam de diversas maneiras o acompanhamento e o desenvolvimento do estudante em tempo real ou próximo disso.

\section{CONSIDERAÇÕES FINAIS}

Como a avaliação é um campo muito vasto e que necessita muita pesquisa, requer inicialmente do professor, um olhar no que: o estudante sabe, como sabe, como pensa e que o processo dever ser parte integrante do ensino. Ainda, o professor não deve dar tanta 
ênfase no que o estudante não sabe, métodos de memorização e contar somente o resultado como processo classificatório (SILVA, DEUSA e MARQUES, 2016). Assim, quanto mais à avaliação se caracterizar como uma proposta construtiva, dinâmica, formativa, dialógica, mediadora e sem segregação (LUCKESI, 2002), mais completa ela será.

O estudo identificou nos trabalhos relacionados um consenso que a avaliação de função formativa é a mais qualificada para verificar as dificuldades, possibilitando inovar e reorganizar ações para o progresso do estudante. Também há uma diversidade de tecnologias que podem auxiliar nas informações diagnósticas de cada interação do estudante com o material de estudo. Basta então, adaptar um modelo de ensino híbrido que melhor adeque as estruturas da instituição de ensino e que nesse se desenvolva as formas de extrair as informações para gerir continuamente o processo de ensino e de aprendizagem.

\section{REFERENCIAS}

ASSIS, M. Contos Sagrados. Rio de Janeiro: Ed. Ouro, 1997.

ANDRADE, M. C. F. SOUZA, P. R. Modelos de Rotação por Ensino Híbrido: estações de trabalho e sala de aula invertida. In: Anais da E-Tech: Tecnologias para Competitividade Industrial, Florianópolis, v.9, n.1, 2016. Disponível em: <http://revista.ctai.senai.br/index.php/edicao01/article/view/773>. Acesso em: 22 mai. 2017.

BACICH, L. Ensino Híbrido: Proposta de formação de professores para uso integrado das tecnologias digitais nas ações de ensino e aprendizagem. In Anais do Workshop de Informática na escola, 2016. Disponível em: http://www.br-ie.org/pub/index.php/wie/article/view/6875>. Acesso em: 27 mai. 2017.

BACICH, L.; TANZI NETO, A.; TREVISANI, F. M. Ensino híbrido: personalização e tecnologia na educação. Porto Alegre: Penso, 2015.

BUCHINGER, D. CAVALCANTI, G. A. S. e HOUNSELL, M. S. (2012). Mecanismo de Busca Acadêmica: uma Análise Quantitativa. Disponível em: $<$ http://www.joinville.udesc.br/portal/professores/avanilde/materiais/11_EP_2012_Buchinger_m ba_melhores_RBCA.pdf>. Acesso em $20 \mathrm{dez} .2016$.

CHRISTENSEN, C.; HORN, M. B.; STAKER, H. Ensino Híbrido: uma Inovação Disruptiva? Uma introdução à teoria dos híbridos. 2013. Disponível em: <https://s3.amazonaws.com/porvir/wpcontent/uploads/2014/08/PT_Is-K-12-blended-learning-disruptive-Final.pdf>. Acesso em: 09 jun. 2017.

COSTA, H.; ROZZETT, K.; CARVALHO, S.; ODELIUS, C. Hibridização no ensino superior: avaliação de uma iniciativa na disciplina Introdução à Administração (Universidade de Brasília). In. Anais da Revista Novas Tecnologias na Educação - RENOTE, v.10, n.3, 2012. Disponível em: < http://seer.ufrgs.br/renote/article/view/36388>. Acesso em: 05 jun. 2017.

DA SILVA, H. R. M. A assistência contínua ao estudante na avaliação em matemática em forma de teia. In. Educação Matemática em Revista, Rio Grande do Sul, n. 17 - v.2 - p. 35 a 49, 2016. Disponível em: <http://sbemrs.org/revista/index.php/2011_1/article/viewFile/207/155>. Acesso em: 27 mai. 2017.

HOBMEIR, E. C. Flipped Classroom: as práticas dos estudantes inseridos nos cursos semipresenciais de gestão. 2016. Disponível em: https://portal.uninter.com/wpcontent/uploads/2017/mestrado/dissertacoes/ELAINE-CRISTINA-HOBMEIR.pdf>. Acesso em: 22 mai. 2017.

HORN, M. B.; STAKER H. Blended: usando a inovação disruptiva para aprimorar a educação. Tradução: MONTEIRO, M. C. G. Porto Alegre, RS: ed. Penso, 2015. 
MORAN, José. Educação Híbrida: um conceito-chave para a educação, hoje. In: BACICH, L.; TANZI NETO, A.; TREVISANI, F. M. (Org.). Ensino híbrido: personalização e tecnologia na educação. Porto Alegre: Penso, 2015.

. Mudando a Educação com Metodologias Ativas. In: Coleção Mídias

Contemporâneas. Convergências Midiáticas, Educação e Cidadania: aproximações jovens. Vol.

II] Carlos Alberto de Souza e Ofelia Elisa Torres Morales (orgs.). PG: Foca Foto-

PROEX/UEPG, 2015. Disponível em: <http://www2.eca.usp.br/moran/wpcontent/uploads/2013/12/mudando_moran.pdf>. Acesso em: 20 mai. 2016.

LUCKESI, C. C. Avaliação da aprendizagem na escola e a questão das representações sociais. In. Eccos revista científica, São Paulo, v. 4, n. 2, p. 79-88, 2002. Disponível em: $<$ http://www.luckesi.com.br/textos/art_avaliacao/art_avaliacao_eccos_1.pdf>. Acesso em: 27 mai. 2017.

PERRENOUD, P. Avaliação: Da Excelência à Regulação das Aprendizagens Entre Duas Lógicas. Porto Alegre: Artmed, 1999.

PIVA Jr., D.; CORTELAZZO, A. L.; FREITAS, F. A. and Belo, R. O. (2016). Sistema de avaliação da aprendizagem (SAA): operacionalização da metodologia "Flipped Classroom”. In Anais do congresso da Abed, Itu, São Paulo, 2016. Disponível em: <http://www.abed.org.br/congresso2016/trabalhos/262.pdf>. Acesso em: 10 jun. 2017.

RODRIGUES, E. F. Educação Híbrida: um conceito-chave para a educação, hoje. In: Bacich, L.; Tanzi Neto, A. and Trevisani, F. M. (Org.). Ensino híbrido: personalização e tecnologia na educação. Porto Alegre: Penso, p.123-140, 2015.

SCHIEHL, E. P; GASPARINI, I. Contribuições do Google Sala de Aula para o Ensino Híbrido. Revista Renote, Rio Grande do Sul. Disponível em: $<$ http://seer.ufrgs.br/index.php/renote/article/view/70684>. Acesso em 10 de mai. 2017.

SILVA, R. M.; DEUSA, M.; MARQUES, R. C. C. B. Modificando, ampliando e ressignificando a avaliação aravés da plataforma MOODLE. In. Simpósio Internacional de Educação a Distância. Disponível em: <http://www.siedenped2016.ead.ufscar.br/ojs/index.php/2016/article/view/1721>. Acesso em: 26 mai. 2017.

STEINERTA, M. E. P.; DE BARROSA, M. P. PEREIRA, M.C. O descompasso entre ensino híbrido e digital divide: docentes de ciências da natureza em foco. In. Revista Ensino, Educação e Ciências Humanas, Londrina, v. 17, n.3, p. 209-215, 2016. Disponível em: <http://pgsskroton.com.br/seer/index.php/ensino/article/view/4158>. Acesso em: 27 mai. 2017.

TANZI NETO, A.; SCHNEIDER, F.; BACICH, L. Tecnologia no Ensino de Língua Adicional: Personalização e Autonomia do estudante por meio de um modelo de Ensino Híbrido. In. Revista CBTecLE, São Paulo, v.1, n.1, 2016. Disponível em: $<$ https://revista.cbtecle.com.br/index.php/CBTecLE/article/view/29>. Acesso em: 25 mai. 2017.

VALENTE, J. A. Blended Learning e as mudanças no ensino superior: a proposta da sala de aula invertida. In. Anais da Educar em Revista, n.4, p.79-97, Curitiba, 2014. Disponível em: < http://www.scielo.br/pdf/er/nspe4/0101-4358-er-esp-04-00079.pdf>. Acesso em: 25 mai. 2017.

ZANOTTO, M. A. C; BIANCHI, P. C, F; SILVA, A. P. R.; REALI, A. M. M. R. Hibridização do ensino em uma IES: delineamento de ações pedagógicas para adoção de $20 \%$ a distância em cursos de graduação presenciais, das autoras. In. Simpósio Internacional de Educação a Distância. Universidade Federal de São Carlos. Disponível em: $<$ http://sistemas3.sead.ufscar.br/ojs/index.php/2014/article/view/742/233>. Acesso em: 19 mai. 2017. 